\title{
EDUCAÇÃO PATRIMONIAL COMO EXPERIÊNCIA INTERDISCIPLINAR: PATRIMÔNIO E MEMÓRIa Na Cidade de Goiás
}

\author{
Andréa Ferreira Delgado* \\ Ilse Leone Borges Chaves de Oliveira*
}

\begin{abstract}
Resumo
A partir das propostas de ensino das Subáreas de História e Português do Cepae, desenvolvemos uma experiência de educação patrimonial com alunos do oitavo ano em 2006. Por meio da apresentação de uma série de textos e atividades que elaboramos para abordar o patrimônio material e imaterial da cidade de Goiás, gostaríamos de discutir alguns eixos teóricos que consideramos fundamentais para a educação patrimonial: a abordagem interdisciplinar, a problematização do conceito de patrimônio, a historicização da intervenção do IPHAN no processo de construção do patrimônio nacional, o debate acerca das interrelaçôes do campo do patrimônio com o turismo e a incorporação da experiência social dos alunos. A memória foi o conceito privilegiado, seja aquela instituída pelo conjunto dos bens tombados, seja a delineada pela escrita de Cora Coralina.

PalaVRas-CHAVE: educação patrimonial, memória, literatura.

\section{Patrimonial education as an interdisciplinary experience: patrimony and memory in the City of Goiás}

\section{Abstract}

We developed an experience of patrimonial educational with eighth grade students from an interdisciplinary pedagogical plan of Portuguese and History at Cepae in 2006. Through the presentation of a number of texts and activities that we elaborated to approach material and non-material patrimony of the city of Goias, we would like to discuss some theoretical axles that we consider essential to the patrimonial education: the interdisciplinary approach, the problematization of patrimonial concept, the historicization of IPHAN intervention in the process of construction of the national patrimony, the debate about the interrelations in the field of patrimony with the tourism and the incorporation of the students's social experience. The memory was the privileged concept, be that instituted by the set of goods put under governmental trust, be that delineated by the writings of Cora Coralina.

KEY WORDS: patrimonial education, memory and literature

* Professora do Departamento de Metodologia de Ensino do Centro de Ciências da Educação da Universidade Federal de Santa Catarina. Doutora em História Cultural pela Unicamp. E-mail: andreadelgado@uol.com.br.

** Professora de Língua Portuguesa do Centro de Ensino e Pesquisa Aplicada à Educação (Cepae/UFG). Doutoranda em Estudos Lingüísticos pela UFG. E-mail: ilseleone@ yahoo.com.br. 


\section{Revista Solta a Voz, v. 19, n. 2}

\section{INTRODUÇÃo}

Nossa prática de ensino de História e de Português, há cerca de cinco anos, está fundamentada na realização de múltiplos projetos interdisciplinares que alteraram profundamente nossa prática pedagógica, desde o planejamento até a avaliação dos alunos e, principalmente, a abordagem dos conteúdos. Nossa aproximação foi estimulada pela proposta de ensino de História (Subárea de História/Cepae, 2004), cujo eixo "o ensino de história como prática de leitura e escrita" e a constante preocupação de associar o estudo do processo histórico com a reflexão acerca da sociedade contemporânea instigam o trabalho com os professores de Português que, por sua vez, estruturam suas aulas para possibilitar que os alunos estejam em constante situação de produção de leitura e de escrita no espaço escolar. Objetiva-se que

o aluno seja capaz de compreender e usar a Língua Portuguesa em diferentes situaçôes enunciativas, seja na forma oral ou escrita, seja para a leitura de enunciados formais e informais, verbais e em composição com não-verbais, percebendo sua constituição como expressão do homem e do mundo. (Projeto de Ensino de Língua Portuguesa, 2006, p. 12)

Acreditamos que a interdisciplinaridade, concebida principalmente como princípio da diversidade e da criatividade, tal como propóe Norberto Etges (1995), possibilita que os professores associem conhecimentos e vivências adquiridos em diferentes trajetórias acadêmicas para propor múltiplas abordagens dos conteúdos escolares, objetivando relacioná-los com as experiências sociais dos alunos. Os itinerários que trilhamos são marcados pelo desejo de inter-relacionar a prática da pesquisa com o trabalho em sala de aula da Educação Básica.

A perspectiva de interdisciplinaridade refere-se, portanto, à prática educativa, na qual operacionalizamos duas concepçôes: a abordagem relacional quando, no desenvolvimento de alguns projetos, o ensinoaprendizagem dos conceitos e procedimentos concernentes às disciplinas de História e Português ocorre, simultaneamente, a partir de um conjunto de aulas que desenvolvem a mesma temática.

Para exemplificar, cita-se o projeto "Alimentação como Prática Cultural” (Delgado e Oliveira, 2004), que articulou a leitura de textos literá- 
rios memorialísticos e de textos não literários - dos gêneros argumentativo, informativo e publicitário - acerca da alimentaçáo na sociedade contemporânea com o estudo do Brasil no período colonial, destacando a formação da culinária brasileira (Maciel, 2004).

Outros exemplos da abordagem relacional ocorreram com a leitura de obras literárias nas aulas de Português que dialogam com os conteúdos históricos em discussão nas aulas de História: a leitura de Escrava Isaura, de Bernardo Guimarães (2004) e de contos de Machado de Assis e Monteiro Lobato na abordagem da escravidão; a leitura de "Oliver Twist", de Charles Dickens (2002), no estudo da sociedade industrial na Inglaterra; e ainda a literatura de viagem para tratar das Grandes Navegaçóes e da Conquista da América.

$\mathrm{Na}$ outra vertente que trabalhamos, realizamos a interdisciplinaridade em uma perspectiva epistemológica, ou seja, da construção interdisciplinar do objeto da prática pedagógica. Em outras palavras, o exercício interdisciplinar ocorre no processo de construção da abordagem dos conteúdos, fundamentada em determinada concepção do discurso literário e histórico. Nesse caso, a prática pedagógica interdisciplinar pode ocorrer apenas nas aulas de uma das disciplinas, geralmente em Português.

Um exemplo foi o projeto intitulado "Memória e tessitura da narrativa: uma experiência escolar de leitura” (Oliveira e Delgado, 2006) que consistiu no estudo interdisciplinar de Menino de engenho, de José Lins do Rego (2003), durante as aulas de Português. Vale ressaltar que os alunos, na série anterior, já haviam lido Doidinho, do mesmo autor (Rego, 1994), num outro projeto elaborado a partir do tema cotidiano escolar. Com o objetivo de analisar as especificidades do discurso memorialístico, destacando também a possibilidade da discussão das relaçóes sociais e de trabalho que estruturam as memórias recordadas, construímos três eixos para trabalhar com Menino de engenho, no $8^{\circ}$ ano: "memória e criação literária", "o jogo temporal na tessitura da narrativa", "o conceito relaçóes de trabalho no texto literário: dependência pessoal e prática do favor”. No processo de análise desses eixos, recorremos à estratégia de propor atividades de exploração do texto literário associadas a textos didáticos que produzimos a partir do estudo da produção da crítica literária da obra de José Lins do Rego (Trigo, 2002; Villaça, 2003) e da produção sociológica a respeito das relaçóes sociais no campo (Vita, 1994).

A experiência que constitui o tema desse texto foi nossa primeira incursão interdisciplinar na educação patrimonial. Individualmente, porém, 
a professora de História investiga a Cidade de Goiás há muitos anos, associada ao estudo da invenção de Cora Coralina como mulher-monumento (Delgado, 2003). A inserção no campo do patrimônio, ao entrelaçar-se com as tarefas cotidianas de ensino na Educação Básica e de formação de professores, resultou na reflexão acerca da educação patrimonial.

A escrita desse texto retoma esses caminhos e, por isso, está organizada em três eixos: explicitação de alguns pressupostos para a educação patrimonial, configuração teórica da abordagem da cidade de Goiás como objeto do campo do patrimônio e a apresentação da experiência pedagógica.

\section{EdUCAÇÃo PATrimonial COMO ObJETO do ENSINO DA HiSTóRIA}

Nossa concepção é que a educação patrimonial deve fundamentarse na problematização do seu objeto. Quer seja na pesquisa histórica, quer seja no ensino de história, o "Patrimônio" precisa ser desnaturalizado e historicizado. Isso significa dizer que os bens tombados e reconhecidos como "patrimônio nacional" não são dados naturais, mas sim produtos das práticas culturais que os engendram.

Se a educação patrimonial for planejada apenas a partir do tripé de "conhecer, preservar e difundir" os bens tombados pelos órgãos públicos, ocorrerá a reprodução de determinadas concepçóes que orientaram a produção do patrimônio local, regional e/ou nacional. Em outras palavras, tanto o trabalho com os bens culturais em sala de aula quanto a visita a monumentos, museus e cidades históricas devem compreender a investigação da sua produção pelos agentes oficiais encarregados de instituir a memória coletiva.

Propomos, então, a abordagem da construção do campo do patrimônio, tal como propóe Maria Cecília Fonseca (1992, p. 23):

É imprescindível questionar o processo de produção desse universo que constitui o patrimônio, os critérios que regem a seleção de bens e justificam sua proteção; identificar os atores envolvidos nesse processo e os objetivos que alegam para legitimar o seu trabalho; definir a posiçáo do Estado relativamente a essa prática social e investigar o grau de envolvimento da sociedade.

O termo "patrimônio" designa, desde a pioneira experiência francesa no período pós-revolucionário, o conjunto de bens de valor cultural 
protegidos legalmente pelo Estado que, em nome do interesse público, deve zelar para que sejam cultuados, preservados e legados às geraçóes futuras. Depois que o órgão estatal responsável por instituir o patrimônio lhes atribui a função de representar a nação, esses bens passam então a ser considerados como propriedade de todos os cidadãos.

No Brasil, a construção do patrimônio nacional resulta de uma política oficial do Estado desenvolvida pelo órgão federal do Patrimônio Nacional, organizado com o nome de Serviço do Patrimônio Histórico e Artístico Nacional (SPHAN) em 1937, denominado atualmente, e na maior parte de sua história, de Instituto do Patrimônio Histórico e Artístico Nacional (IPHAN). Desde então, para passar a integrar o patrimônio nacional, os bens seguem uma trajetória: especialistas constroem um estudo detalhado sobre esse bem a fim de justificar seu valor e a importância de sua conservação. $\mathrm{O}$ reconhecimento oficial desse valor se faz pelo tombamento, isto é, pela inscrição do bem em um dos quatro "Livros do Tombo": "Arqueológico, etnológico e paisagístico"; "Histórico"; "das Belas-artes" e "das Artes aplicadas". A partir do tombamento, esse bem deve ser preservado, protegido de qualquer dano ou destruição, para usufruto no presente e no futuro.

A constituição do campo do patrimônio no Brasil, portanto, resulta das estratégias discursivas e não-discursivas do Instituto do Patrimônio Histórico e Artístico Nacional (IPHAN), que produziram a noção de "patrimônio nacional" ao realizar o trabalho de produção, gestão e imposição de determinados bens culturais como memória coletiva da nação (Santos, 1996).

Enquanto modalidade de construçâo da memória e da identidade nacional e, portanto, de objetivação da idéia de nação, o "patrimônio nacional" é produto das relaçôes de saber e poder (Foucault, 1985) que o engendram. Assim, para delinear a trajetória do campo do patrimônio no Brasil, torna-se necessário inventariar as práticas discursivas (Foucault, 1987) que traçam as configuraçóes assumidas pelo IPHAN nos períodos de sua história, resultando na implantação de diferentes políticas de preservação, de acordo com a concepçáo do que, para quem e por que preservar.

Em resumo, propomos incorporar aos objetivos dos projetos de educação patrimonial a discussão do conceito de patrimônio, a historicização de suas múltiplas acepçóes e a investigação das políticas públicas de construção e preservação do patrimônio no Brasil. 


\section{A Cidade de Goiás COMO ObJETo do CAMPo do PATRIMÔNio}

A Cidade de Goiás é objeto privilegiado da história do patrimônio no Brasil e, por extensão, da educação patrimonial: desde os anos 1950 foi incorporada ao mapa do Patrimônio Nacional pela açáo da Diretoria do Patrimônio Histórico e Artístico Nacional (DPHAN), denominação do órgão estatal na época, e é detentora do título de "Patrimônio da Humanidade", concedido pela Organização das Naçôes Unidas para a Educação, Ciência e Cultura (Unesco), em 2001.

São múltiplos os itinerários que a prática pedagógica pode percorrer para explorar a Cidade de Goiás. É nossa concepção de educação patrimonial, esboçada acima, que vai delinear as trajetórias de construção de uma proposta de educação patrimonial.

Ao invés de compreender o patrimônio na Cidade de Goiás como resultado da configuração no espaço urbano dos bens materiais que são suporte da memória nacional e regional e que, a partir desse acontecimento, cabe aos professores praticar a educação patrimonial que resulte no reconhecimento do valor histórico desta cidade e na sua preservação, propomos seguir outro caminho: tentar desconstruir esse processo ou, em outras palavras, revelar as imbricadas teias de constituição e naturalização de Goiás como cidade histórica e turística. Ou seja, a problematização do próprio objeto é um dos conteúdos que desenvolvemos em nossas práticas pedagógicas de educação patrimonial.

O reconhecimento de Goiás como cidade histórica não pode ser explicado apenas pelo fato de ter sido capital por mais de duzentos anos e conservar na estrutura urbana as construçóes do século XVIII. A inserção de Goiás no mapa do patrimônio não se justifica simplesmente pelo desejo de preservar esses bens como vestígios do passado, cujos valores seriam supostamente intrínsecos aos objetos e pré-existentes a qualquer classificação.

O poder de evocar, testemunhar e eternizar o passado não é resultado de qualquer característica inerente aos objetos tombados. Ao contrário, os discursos produzidos no campo do patrimônio são importantes instrumentos de delimitação da memória coletiva nas sociedades contemporâneas.

O órgão do Patrimônio Nacional não atua para revelar o valor estético e histórico dos bens; pelo contrário, ele institui esses valores no processo de tombamento e nas práticas de intervenção e preservação. Ou seja, 
a cidade de Goiás somente passou a ter visibilidade como lugar histórico quando foi inscrita na rede discursiva do patrimônio, à medida que o tecido da linguagem lhe foi atribuindo determinados conteúdos para torná-la símbolo da memória coletiva.

Investigar a instituição de Goiás como cidade histórica é, portanto, indagar acerca dos atores e dos processos de "enquadramento da memória", na acepção de Michel Pollack (1989), quer dizer, do trabalho de constituição, formalização e imposição da memória coletiva.

No processo de constituição de conteúdos para o passado, o investimento para solidificar e dotar de duração e estabilidade uma determinada memória para representar o conjunto da sociedade configura operaçóes de seleção, organização e uniformização da multiplicidade de significados atribuídos ao passado. Nessa perspectiva teórica, a memória coletiva é concebida enquanto coerção, como "imposição, uma forma específica de violência simbólica” (Pollack, 1989, p. 3).

A declaração e classificação de algumas cidades como "históricas" atribui territorialidade à história que as instituiçôes dotadas do poder de consagrar os símbolos nacionais querem perpetuar, engendrando "lugares da memória", como nos ensina Pierre Nora (1993, p. 18), onde a estabilidade e preservaçáo do espaço favorecem "o relembrar e o reencontrar do pertencimento, princípio e segredo da identidade” que se pretende uniformizar e impor como nacional ou regional.

A objetivação da cidade de Goiás como "lugar da memória" resulta de uma série de estratégias que se entrelaçam: a incorporação na ordem do discurso do Patrimônio Nacional, a invenção das tradiçóes locais e a monumentalização de Cora Coralina como símbolo emblemático da cidade. A investigação dessas práticas discursivas que trabalham as relações entre o espaço, o tempo e a história para conferir visibilidade e sentidos a esta cidade foram objetos de artigos produzidos por Delgado (2005a; 2005b) e constituíram a trama histórica que orientou nossa experiência pedagógica interdisciplinar de educação patrimonial.

\section{LITERATURA E PATRIMÔNIO: A CONSTRUÇÃO DA MEMÓRIA COLETIVA}

Para traçar uma trajetória de educação patrimonial para a cidade de Goiás, associamos patrimônio e literatura a partir da idéia de que ambos são estratégias de produção da memória coletiva na sociedade contempo- 


\section{Revista Solta a Voz, v. 19, n. 2}

rânea. Ao mesmo tempo, entrelaçamos patrimônio material e imaterial ao abordar o patrimônio configurado nos bens tombados pelo IPHAN amalgamado com a escrita da memória de Cora Coralina.

Outro eixo de abordagem do patrimônio imaterial foi construído para estabelecer a ligação com o projeto de ensino "A alimentação como prática cultural" que desenvolvemos anteriormente com essas turmas: privilegiamos a questão de práticas culturais associadas à alimentação no estudo da escrita autobiográfica de Cora Coralina (Delgado, 2002).

Ao associar "conjuntos urbanos de valor histórico", "criações artísticas", "modos de fazer" relacionados às práticas de alimentação e tratá-los enquanto bens culturais cuja produção está estreitamente relacionada com a cidade de Goiás, operamos com o conceito de "patrimônio cultural" tal como conceituado no artigo 216, Seção II - DA CULTURA, da atual Constituição Brasileira: "Constituem patrimônio cultural brasileiro os bens de natureza material e imaterial, tomados individualmente ou em conjunto, portadores de referência à identidade, à ação, à memória dos diferentes grupos de formadores da sociedade brasileira" (Constituição da República Federativa do Brasil/1988, artigo 216, 2006, p. 137).

Assim como ocorreu em outros projetos de ensino que desenvolvemos (Oliveira e Delgado, 2008), a prática da leitura entrelaça-se ao estudo do processo histórico, visando articular presente e passado, a partir de temas do cotidiano e da prática social, com o objetivo de tornar a aprendizagem significativa para os alunos.

Para realizar a mediação didática (Lopes, 1997a; 1997b), compreendida aqui como um conjunto de estratégias que os professores agenciam para articular os elementos teóricos advindos da produção acadêmica com um fazer pedagógico planejado a partir das experiências e conhecimentos cotidianos dos alunos, optamos por produzir materiais didáticos, concebidos como suporte para a explicação e problematização realizadas pelas professoras, a partir de metodologias que estimulam constantemente a participação dos alunos.

Embora os limites desse texto não permitam a reprodução e discussão dos materiais didáticos, vamos delinear os itinerários entrelaçados que compuseram a trajetória dessa experiência de educação patrimonial, tomando-os como referência para aproximar o leitor dos conteúdos e estratégias pedagógicas operacionalizadas em sala de aula. 


\section{a) Os tempos da memória e a cCdade de Goiás}

Os alunos leram uma coletânea de poemas e de crônicas de Cora Coralina (Coralina, 1984; 1993; 1994; 2001) que organizamos a partir de determinada interpretação da sua obra: o amálgama entre reminiscências autobiográficas e memorialismo está na tessitura da escrita da memória de Cora Coralina que é, a um só tempo, momento de construção de uma memória autobiográfica e uma forma específica de criação da memória coletiva (Delgado, 2003).

Para explorar esses dois eixos e delinear uma estratégia de leitura, elaboramos uma atividade com dupla inflexão: propusemos questôes de interpretação dos poemas "Menina mal amada", "Minha infância" e "Moinho do tempo" para enfocar a autobiografia poética escrita por Cora Coralina e, ao elaborar questóes que interligavam a educação das crianças com as práticas alimentares nos poemas "Normas de educação" e "Antiguidades", abordamos o memorialismo.

Em seguida, a professora de Português trabalhou com o texto "Os tempos da memória e a Cidade de Goiás”, composto de trechos do artigo "Cora Coralina e a invenção de si" (Delgado, 1999). Nosso objetivo foi investigar o entrelaçamento entre as vivências do espaço e o enredo rememorado, considerado como principal estratégia da escrita da memória produzida pela poeta. Privilegiamos comentários e citaçóes de poemas memorialistas, nos quais a "memória topográfica" (Bolle, 1994) de Cora Coralina tece o tempo e o espaço num só movimento, delineando imagens da cidade de Goiás por meio de experiências individuais e coletivas, tornando-a espessa de múltiplos sentidos, temporalidades e memórias.

A autobiografia de Cora Coralina vai sendo elaborada à medida que a Velha Casa da Ponte e a Cidade de Goiás emergem das reminiscências, tecendo a relação entre as vivências do espaço e o enredo rememorado. $\mathrm{Na}$ descrição do espaço público da cidade, a autobiografia cede lugar ao memorialismo e o olhar da escritora está menos voltado para as experiências individuais do que para as experiências coletivas, menos voltado para a vivência interior do que para o compartilhar eventos (Delgado, 1999).

Trabalhar esse texto com os alunos foi um exercício de incorporação da crítica literária na construção do conhecimento escolar (Chervel, 1990; Forquin, 1993), pois o artigo transformado em suporte da mediação didática, propiciou analisar a obra de Cora Coralina por meio de conceitos teóricos 


\section{Revista Solta a Voz, v. 19, n. 2}

que, inter-relacionados com práticas de leitura dos alunos, possibilitaram a compreensão da literatura como estratégia de construção da memória coletiva. Ao mesmo tempo, os poemas de Cora Coralina incitaram os alunos a traçar em seus próprios percursos na cidade, preparando a abordagem acerca do patrimônio e a visita que realizamos a Goiás.

\section{b) Patrimônio Nacional}

A abordagem teórica do patrimônio e das práticas de tombamento em Goiás, conduzida pela professora de História, também ocorreu nas aulas de Português. Produzimos o material didático "Patrimônio Nacional" para introduzir e historicizar a noção de "patrimônio histórico e artístico nacional”, tal como foi construída na Europa no final do século XIX, quando o Estado assumiu, em nome do interesse público, as tarefas de selecionar os bens que simbolizam a nação e de exercer a proteção legal desses bens, que passam a ser propriedade da nação e devem ser preservados e legados para as geraçóes futuras (Fonseca, 1992).

Para desenvolver esse conteúdo elaboramos dois textos: o primeiro, "A Revolução Francesa e a produção da noção de patrimônio nacional", com o objetivo de estudar as relaçôes entre patrimônio e a objetivação simbólica da nação ou, em outras palavras, entre a constituição do conceito de "patrimônio nacional" como estratégia de invenção de uma identidade coletiva denominada de "identidade nacional". O segundo texto, "Construção do patrimônio: uma ação política de gestão do passado", possibilitou a discussão dos significados das estratégias do Estado para produção e preservação do patrimônio nacional, destacando a criaçáo do IPHAN e os mecanismos de tombamento no Brasil.

No final desse material didático, reproduzimos três documentos que permitem investigar, tal como consta no título, as "Concepções de Patrimônio na Legislação Brasileira” e suas transformações ao longo do tempo: o Decreto-Lei n. 25, de 20 de novembro de 1937, promulgado pelo presidente Getúlio Vargas, que define o "Patrimônio Histórico e Artístico nacional" a partir dos critérios de vinculação "a fatos memoráveis da História do Brasil" e por seu "excepcional valor arqueológico ou etnográfico, bibliográfico ou artístico” (MEC-SPHAN/Pró-Memória, 1980, p. 111) e, assim, orienta a política de tombamento do recém-criado Serviço do Patrimônio Histórico e Artístico Nacional (SPHAN); o art. 216 da Consti- 
tuição de 1988, que amplia a noção de patrimônio cultural e o Decreto n. 3.551, de 4 de agosto de 2000, que "institui o Registro de Bens Culturais de Natureza Imaterial que constituem o patrimônio cultural brasileiro" e cria o Programa Nacional do Patrimônio Imaterial (Sant'Anna: 2003; Fonseca, 2003).

A análise de documentos históricos em sala de aula é recorrente, pois constitui um dos eixos da proposta metodológica de ensino de História no Cepae. Nesse caso, os documentos foram problematizados à medida que o próximo material didático era estudado, visando relacionar as concepçóes de patrimônio configuradas na legislação com as políticas de Estado que orientaram, em diferentes momentos, as práticas de intervenção do Instituto do Patrimônio Histórico e Artístico Nacional na Cidade de Goiás.

\section{c) A instituiçáo de Goiás como cidade histórica}

Para trabalhar a concepção teórica de que a Cidade de Goiás somente passou a ter visibilidade como lugar histórico quando foi inserida no mapa do patrimônio por meio da atuação do IPHAN (Delgado, 2003; 2005a), o texto foi dividido em três itens: a) "O tombamento de bens isolados”, no início da década de 1950, quando o SPHAN chegou à cidade de Goiás para fazer o tombamento dos principais edifícios públicos e religiosos, que representavam o acervo arquitetônico do século XVII, a partir da concepção de consagrar determinados bens imóveis como monumentos históricos; b) "A delimitação do centro histórico" pelo IPHAN, em 1978, que incluiu o entorno dos principais monumentos no âmbito da proteçáo do patrimônio, denotando mudanças no campo discursivo do patrimônio e a incorporação progressiva do turismo nas políticas públicas; c) "Goiás como Patrimônio da Humanidade", título concedido pela Unesco em 2001, que inaugura a atual fase vivenciada pela cidade, caracterizada pelo aumento do fluxo turístico.

Ao abordar a construção do mapa do patrimônio no Brasil (Rubino, 1996) nos trinta primeiros anos de atuação do IPHAN, destacamos o privilégio dado aos "monumentos de pedra e cal", preferencialmente os que representam a arquitetura religiosa e a estatal do século XVIII. Por meio dessas características, refletimos acerca do quanto a construção do patrimônio é seletiva, preservando aqueles prédios que testemunhavam o poder religioso, político e militar da elite para a construção da identidade 


\section{Revista Solta a Voz, v. 19, n. 2}

histórica e cultural da nação brasileira. Ao mesmo tempo, alijando do campo do patrimônio os vestígios, por exemplo, dos templos não-católicos, das senzalas e dos bairros operários.

No segundo momento de intervenção do IPHAN na Cidade de Goiás, em 1978, o entorno dos principais monumentos foi incluído no âmbito de proteção do patrimônio, delimitando um centro histórico. Para contextualizar essa ação, abordamos as transformaçóes no campo discursivo do patrimônio histórico, principalmente com incorporação de uma categoria que se torna fundamental para a compreensão das políticas públicas nas cidades históricas desde então: o turismo cultural.

Para tratarmos o momento atual vivenciado pela cidade de Goiás, agenciamos os conhecimentos dos alunos mobilizados pelo aumento da presença da cidade na mídia desde o título de "Patrimônio da Humanidade" concedido pela Unesco, em 2001, depois de intensa mobilização que reuniu várias entidades culturais da Cidade de Goiás e os governos municipal e estadual, com o apoio do governo federal por meio do IPHAN.

Durante as aulas, trabalhamos com um mapa da cidade de Goiás elaborado pelo IPHAN que permite visualizar as diferentes fases de intervenção do órgáo estatal no espaço urbano, visto que estão demarcados os bens isolados "Tombados em 1950/51", a "Extensão do tombamento do Conjunto Arquitetônico e Urbanístico em 1978”, a "Zona de preservação histórica" e a "Área de entorno de preservação do Núcleo Histórico".

Esse mapa foi utilizado também como estratégia para estimular novas leituras dos poemas de Cora Coralina. Solicitamos que cada aluno elaborasse uma legenda e produzisse um "Mapa da memória de Cora Coralina”, relacionando o Rio Vermelho e suas pontes, as ruas da cidade e os bens tombados com os poemas onde esses marcos urbanos são objetos da escrita da memória.

A obra da poeta delineia um "mapa da memória", na acepção de Cristina Freire (1997, p. 70), "vivencial e narrativo", onde os lugares "estão amarrados às histórias”. Esse mapa foi utilizado como peça de múltiplas estratégias no processo de produção da cidade histórica e turística (Delgado, 2005a). No trabalho pedagógico, essa noção de mapa da memória foi reapropriada na prática da educação patrimonial.

O mapa constituiu recurso fundamental durante a visita a Goiás. Os alunos foram estimulados a utilizá-lo constantemente como instrumento de orientação para percorrer as ruas da cidade e localizar os monumentos. 
Ao explorar as duas legendas - a que demarcava a intervenção do IPHAN e aquela que eles mesmos tinham elaborado com os marcos da memória de Cora Coralina -, os alunos eram guiados pela memória coletiva, configurada tanto pelos bens tombados quanto pela produção literária.

Os mapas construídos pelos alunos foram diferentes entre si, pois cada um escolheu os poemas que desejava representar no "Mapa da memória de Cora Coralina", demonstrando, com isso, uma percepção individual da leitura da coletânea. Entretanto, eles têm um ponto em comum: a ação do órgão federal responsável pela instituição e preservaçáo do patrimônio foi amalgamada com a escrita da memória. Com isso, consideramos que conseguimos sintetizar a noção de patrimônio material e imaterial.

Além disso, a partir da leitura que realizou da obra de Cora Coralina, cada aluno traçou um novo mapa para entretecer o rememorar do tempo aos espaços da cidade, reelaborando sentidos e significados para a memória coletiva configurada no mapa produzido pelo IPHAN. Ao propiciar que os alunos se tornem artífices dos complexos mecanismos de reproduçáo e preservação da memória, essa atividade pode ser considerada como síntese da nossa experiência de educação patrimonial.

\section{REFERÊNCIAS}

BOLLE, W. Fisionomia da metrópole moderna: representação da história em Walter Benjamin. São Paulo: USP, 1994.

BRASIL. Constituição da República Federativa do Brasil. Texto constitucional promulgado em 5 de outubro de 1988. Brasília: Senado Federal/ Subsecretaria de Ediçôes Técnicas, 2006.

CHERVEL, A. História das disciplinas escolares: reflexôes sobre um campo de pesquisa. Teoria \& Educação, Porto Alegre, v. 2, p. 177-229, 1990.

CORALINA, C. Meu livro de cordel. São Paulo: Global, 1994.

. Poemas dos becos de Goiás e estórias mais. São Paulo: Global, 1993. - Villa Boa de Goiás. São Paulo: Global, 2001.

- Vintém de cobre - meias confissóes de Aninha. Goiânia: Editora da Universidade Federal de Goiás, 1984. 
DELGADO, A. A invenção de Cora Coralina na batalha das memórias. Tese (Doutorado em História). Universidade Estadual de Campinas, Campinas, 2003.

. Cora Coralina: a poética do sabor. Ilha - Revista de Antropologia - Programa de Pós-Graduaçáo em Antropologia Social, Florianópolis, v. 4, n. 1, p. 59-83, 2002.

. Cora Coralina e a invenção de si. Educação, Subjetividade \& Poder, Porto Alegre, v. 6, p. 42-54, 1999.

. Goiás: a invenção da cidade "Patrimônio da Humanidade". Horizontes Antropológicos, Porto Alegre, n. 22, p. 113-143, 2005 a.

. Museu e memória biográfica: um estudo da "Casa de Cora Coralina”. Sociedade e Cultura, Goiânia, v. 8, n. 2, p. 103-117, 2005 b.

; OLIVEIRA, I. A alimentação como prática cultural: uma experiência interdisciplinar de ensino de História e Português. Revista Solta a Voz, Goiânia, v. 15, n. 2, p. 95-107, 2004.

DICKENS, C. Oliver Twist. São Paulo: Ediouro, 2002.

ETGES, N. J. Ciência, interdisciplinaridade e educação. In: JANTSCH, A.; BIANCHETTI, L. (Orgs). Interdisciplinaridade: para além da filosofia do sujeito. Petrópolis: Vozes, 1995. p. 51-84.

FONSECA, M. C. Para além da pedra e cal: por uma concepção ampla de patrimônio cultural. In: ABREU, R.; CHAGAS, M. (Orgs.). Memória e patrimônio: ensaios contemporâneos. Rio de Janeiro: DP\&A, 2003. p. 56-76.

- Construçóes do passado: concepções sobre a proteção do patrimônio histórico e artístico nacional (Brasil: anos 70-80). Tese (Doutorado em Sociologia). Universidade de Brasília, Brasília, 1992.

FORQUIN J. Escola e cultura: as bases epistemológicas do conhecimento escolar. Porto Alegre: Artes Médicas, 1993.

FOUCAULT, M. A arqueologia do saber. Rio de Janeiro: Forense Universitária, 1987.

. Microfísica do poder. Rio de Janeiro: Graal, 1985. 
FREIRE, C. Além dos mapas: os monumentos no imaginário urbano contemporâneo. São Paulo: Annablume, 1997.

GUIMARÁES, B. A Escrava Isaura. Barueri: Gráfica e Editora do Brasil, 2004. (Coleção Clássicos da Literatura)

LOPES, A. Conhecimento escolar: inter-relaçóes com conhecimentos científicos e cotidianos. Contexto e Educação, Ijuí - RS, n. 45, p. 40-59, jan./mar., 1997a.

LOPES, A. Conhecimento escolar: processos de seleção cultural e de mediação didática. Educação \& Realidade, Porto Alegre, n. 22, p. 95-111, jan./jun., 1997b.

MACIEL, M. E. Uma cozinha à brasileira. Estudos Históricos, Rio de Janeiro, n. 33, p. 1-16, 2004.

MEC-SPHAN/Pró-Memória. Proteção e revitalização do patrimônio cultural no Brasil: uma trajetória. Brasília: Publicações da Secretaria do Patrimônio Histórico e Artístico Nacional, n. 31, 1980.

NORA, P. Entre memórias e história. A problemática dos lugares. Projeto História, São Paulo, n. 10, p. 7-28, 1993.

OLIVEIRA, I., DELGADO, A. Memória e tessitura da narrativa: uma experiência escolar de leitura. Revista Solta a Voz, Goiânia, v. 17, n. 2, p. 119-133, 2006.

. O entrelaçamento de literatura e memória em experiências interdisciplinares de ensino de Português e História. Revista Solta a Voz, Goiânia, v. 19, n. 1, p. 45-61, 2008.

POLLAK, M. Memória, esquecimento, silêncio. Estudos Históricos, Rio de Janeiro, v. 2, n. 3, p. 3-15, 1989.

REGO, J. L. do. Doidinho. Rio de Janeiro: José Olympio, 1994. . Menino de Engenho. Rio de Janeiro: José Olympio, 2003.

RUBINO, S. B. O mapa do Brasil passado. Revista do Patrimônio Histórico e Artístico Nacional, Rio de Janeiro, v. 24, p. 97-105, 1996.

SANT'ANNA, M. A face imaterial do patrimônio cultural: os novos instrumentos de reconhecimento e valorização. In: ABREU, R.; CHAGAS, 


\section{Revista Solta a Voz, v. 19, n. 2}

M. (Org.). Memória e patrimônio: ensaios contemporâneos. Rio de Janeiro: DP\&A, 2003. p. 46-55.

SANTOS, M. V. M. Nasce a Academia SPHAN. Revista do Patrimônio Histórico e Artístico Nacional, Brasília, n. 24, p. 77-95, 1996.

TRIGO, L. Engenho e memória - o Nordeste do açúcar na ficção de José Lins do Rego. Rio de Janeiro: TopBooks, 2002.

Recebido em: 30 out. 2008

Aceito em: 23 nov. 2008 